\title{
"Diversity of Plants and their Role in Nature"
}

Patel DK ${ }^{*}$

Rural Technology Department, Guru Ghasidas Vishwavidyalaya, Bilaspur, Chhattisgarh, India

*Corresponding author: Patel DK, Professor, Rural Technology Department, Guru Ghasidas Vishwavidyalaya, Bilaspur, Chhattisgarh, India, Tel: 7752260353; E-mail: dplantscience@yahoo.co.in

Received date: June 11, 2015; Accepted date: June 15, 2015; Published date: June 22, 2015

Copyright: (C) 2015, Patel DK. This is an open-access article distributed under the terms of the Creative Commons Attribution License, which permits unrestricted use, distribution, and reproduction in any medium, provided the original author and source are credited.

\section{Editorial}

Plants are a large group of living components in nature. Plants are also marked as a key segment with wide range of significance in formation of global biodiversity. As Biodiversity is an association of all living parts of the nature from different possible natural habitats. Each one organism is of a great value in their structure and function in certain ecosystem/ecological zones. Nature is a complex association of different components and can be differentiated in two major groups such as living and non-living beings.

Presence and valuation of each one component is unique for better regulation and for maintaining existence of species diversity needed for successful growth of the ecosystem. There is always a struggle between environment and biota. It is due to similar requirements of the individuals of a species at the same time if there is a limited source needed for the various purposes of the living beings. Life pattern, seasonal variation, presence, association, competition etc. are different among the population. It is showing similar trends for their uniqueness for a specific species.

Non-living ecological factors are also marked as an environmental factor that includes Water, Soil, and Light etc., whereas living factor associated with the presence of plants, animals and microbes. Each one factors performing certain role in nature which support interdependency of the varied living species. Plants are known as producers are important for reduction of pollution level and also a source of energy by trapping solar radiations to convert in to chemical energy (Sources of energy) in their photosynthesis activities.

Animals are referred as consumers (Herbivores) which are dependent for energy in green plants, carnivores dependent on herbivores. This dependency of organisms forms a food chain and it is also a source of development of food web in nature. It is key and remarkable relationship among the varied group of organisms in nature.

Each species have their certain life period. This period may be differing among various individuals as many of the natural and other factors directly or indirectly affecting it. Death is an important part of life and is also significant for balancing the different ecosystem in different ecological zones. After completing a certain phase of life each one living organism finally dead. Dead body of the organisms are decomposed by the microbes are known as decomposers. Their role is remarkable for avoiding the storage of dead bodies in nature.

Finally it is concluded that the diversity of the plants are a major components of nature not only important for their value as a source of energy but they are also having wide potential to protect the environment in multifold directions. A plant provides better environment and platform to all the living beings in healthy development of the nature. 